\title{
Pituitary Lesions, Obesity, and Mesenteric Lipomas in Insulin-Resistant Horses
}

\author{
Kimberly M. Newkirk ${ }^{1}$, Kelly A. Chameroy², Elizabeth M. Tadros², Barton W. Rohrbach1, \\ Nicholas Frank ${ }^{2}$ \\ ${ }^{1}$ Department of Biomedical and Diagnostic Sciences, College of Veterinary Medicine, University of Tennessee, \\ Knoxville, TN, USA \\ ${ }^{2}$ Department of Large Animal Clinical Sciences, College of Veterinary Medicine, University of Tennessee, \\ Knoxville, TN, USA \\ Email: ${ }^{*}$ knewkirk@utk.edu
}

Received 24 July 2014; revised 10 August 2014; accepted 20 August 2014

Copyright (C) 2014 by authors and Scientific Research Publishing Inc.

This work is licensed under the Creative Commons Attribution International License (CC BY).

http://creativecommons.org/licenses/by/4.0/

(c) (i) Open Access

\section{Abstract}

The aim of the current study was to identify associations between pituitary lesions, body condition scores, and mesenteric lipomas in horses with insulin resistance. Necropsy examinations were performed following euthanasia in 30 adult horses designated as insulin resistant $(n=11)$ or insulin sensitive $(n=19)$. Insulin sensitivity was determined using the insulin-modified frequently sampled intravenous glucose tolerance test and resting insulin concentrations. At necropsy, mesenteric lipomas were measured. The pituitary and adrenal glands, pancreas, and liver were evaluated histologically; pituitary glands were scored based on published criteria. Insulin-resistant horses had significantly higher pituitary scores $(p=0.0035)$ and body condition scores $(p=$ $0.0001)$, even when adjusting for age, and a greater frequency of mesenteric lipomas $(p=0.014)$ and greater lipoma area $(p=0.0332)$ than insulin-sensitive horses. Regardless of insulin status, horses with pituitary scores $\geq 3$ (diffuse hyperplasia; $n=25$ ) had higher body condition scores $(p=$ $0.0313)$ and a greater frequency of mesenteric lipomas $(p<0.0002)$ than those with lower pituitary scores. High body condition score was not correlated to an increased frequency of mesenteric lipomas. Detection of higher pituitary scores in insulin-resistant horses suggested an association between insulin resistance and pituitary morphology. Horses in the insulin-resistant group and those with high pituitary scores had higher body condition scores and a greater frequency of mesenteric lipomas. These horses might be at increased risk for lipoma-associated colic.

\section{Keywords}

Body Condition Score, Horse, Insulin Resistance, Mesenteric Lipoma, Pituitary

\footnotetext{
${ }^{*}$ Corresponding author.
}

How to cite this paper: Newkirk, K.M., Chameroy, K.A., Tadros, E.M., Rohrbach, B.W. and Frank, N. (2014) Pituitary Lesions, Obesity, and Mesenteric Lipomas in Insulin-Resistant Horses. Open Journal of Veterinary Medicine, 4, 190-196. 


\section{Introduction}

Insulin resistance (IR) is broadly defined as a decrease in tissue responsiveness to circulating insulin, resulting in decreased insulin-mediated glucose uptake into skeletal muscle, and adipose and liver tissues [1]. In horses, IR and obesity often occur concurrently; the increased insulin secretion that accompanies obesity can result in hyperinsulinemia, which exacerbates IR [2] [3]. Some horses and ponies in the early stages of IR are able to compensate by increasing pancreatic insulin secretion to maintain normoglycemia [4]. In these horses, insulin concentrations can increase dramatically after feeding, and as the condition progresses, fasting hyperinsulinemia develops. Diagnostic tests for IR include one-time measurement of fasting insulin concentration and measuring insulin sensitivity via the insulin-modified, frequently-sampled intravenous glucose tolerance test (FSIGTT) [5]. Fitting of FSIGTT data to a compartmental population model provides sensitivity to insulin (SI) values, which are then used to identify IR animals [6].

Furthermore, in obese horses, an increase in mesenteric fat can predispose them to the development of mesenteric lipomas [7]. Mesenteric lipomas are common findings at necropsy and may be incidental or a cause of colic when they encircle the intestine and result in a strangulating lesion [8]. In humans, obesity has also been associated with increased oxidative stress and inflammation [9]. Similarly, in horses, increased levels of the acute phase protein serum amyloid A (SAA), which are indicative of systemic inflammation and oxidative stress, have been associated with both obesity and IR [10]. However, it is unclear if the increased SAA is a cause or effects of the obesity and IR. In addition, previous reports have associated IR with pituitary pars intermedia lesions [11]-[13]. Horses with pituitary lesions have been shown to have increased body condition scores (BCS) [14].

Because both IR and pituitary pars intermedia dysfunction (PPID) can be associated with obesity, and since obesity can predispose horses to mesenteric lipomas, we aimed to characterize the associations between IR, post-mortem pituitary lesions, and obesity with mesenteric lipomas. Specifically, these factors are evaluated to determine whether they are associated with the presence and size of mesenteric lipomas.

\section{Materials and Methods}

\subsection{Animals}

The IR horses were part of an existing research herd at the University of Tennessee. Additional donated horses were screened for inclusion as insulin-sensitive (IS) horses. The study was approved by the University of Tennessee Institutional Animal Care and Use Committee.

\subsection{Case Selection}

The IR horses were previously designated as such based on a resting insulin of greater than $20 \mu \mathrm{U} / \mathrm{mL}$ and on the results of FSIGTT tests, as previously described [6] [15]. Briefly, plasma and serum samples were collected via an intravenous (IV) catheter into serum tubes containing sodium fluoride/potassium oxalate. Samples were collected at $-10,-5$, and 0 min relative to dextrose infusion, and values were averaged to obtain the baseline. An IV bolus of $50 \%$ dextrose solution (Vedco, Inc.) was then administered at a dosage of $150 \mathrm{mg} / \mathrm{kg} \mathrm{body}$ weight. Blood glucose and insulin concentrations were measured at 1, 2, 3, 4, 5, 6, 7, 8, 10, 12, 14, 16, and 19 minutes after dextrose infusion. A bolus of regular insulin (Humulin R, Eli Lilly and Co.; $30 \mathrm{mU} / \mathrm{kg}$ body weight) was administered IV at 20 minutes. Plasma and serum were subsequently collected at 22, 23, 24, 25, 27, $30,35,40,50,60,70,80,90,100,120,150$, and 180 minutes. Sodium fluoride/potassium oxalate tubes were immediately cooled on ice, and serum tubes were allowed to clot at room temperature for 1 hour. Tubes were centrifuged at $1000 \times \mathrm{g}$ for 10 minutes, and plasma or serum was harvested and stored at $-20^{\circ} \mathrm{C}$ until analyzed. Plasma glucose concentrations were measured in duplicate using a colorimetric assay (Glucose, Roche Diagnostic Systems) on an automated discrete analyzer (Cobas Mira, Roche Diagnostic Systems). Serum insulin concentrations were measured in duplicate using a radioimmunoassay (Coat-A-Count Insulin, Diagnostic Products) previously validated for use with equine plasma in the authors' laboratory and by others [16]. Intra-assay coefficient of variation $<5 \%$ was required for acceptance of glucose assay results, and $<10 \%$ was required for acceptance of insulin assay results. Minimal model [2] parameters for insulin sensitivity (SI), glucose effectiveness $(\mathrm{Sg})$, acute insulin response to glucose (AIRg), and disposition index (DI) were calculated as previously described [3] [17] using computer software (Stata 9.2, Stata Corp.; MinMod Millennium, version 6.10, Raymond Boston, University of Pennsylvania). Insulin resistance was defined by an SI value of less than $1.0 \times 10^{-4}$ 
$\mathrm{L} \cdot \mathrm{min}^{-1} \cdot \mathrm{mU}^{-1}$.

The group of IS horses was assigned by screening donated horses for insulin sensitivity based on a resting insulin of less than $20 \mu \mathrm{U} / \mathrm{mL}$. All horses were euthanized by IV barbiturate (Beuthanasia D, Schering-Plough Animal Health) overdose.

\subsection{Necropsy}

Horses were necropsied immediately following euthanasia. At necropsy, the mesenteric lipomas were measured (length and width) and the area of each calculated. Since some horses had large numbers of lipomas, only the five largest mesenteric lipomas were measured. For each horse, the area of each lipoma was summed to obtain the total lipoma area. For horses without lipomas, the total lipoma area was 0 . The liver, pancreas, pituitary, and adrenal glands were collected, fixed in formalin, and evaluated microscopically for any lesions. Pituitaries were sectioned, evaluated microscopically, and scored according to published criteria (1, normal, to 5, macroadenoma) [18]. From complete cross sections of both the right and left adrenals, the adrenal cortical and medullary thicknesses were measured with an ocular micrometer. The combined sums of the cortical and medullary thicknesses from each adrenal gland were used to determine the final corticomedullary ratio.

\subsection{Statistical Methods}

Summary statistics for continuous variables are reported as median and interquartile range. A $t$ test and nonparametric Wilcoxon rank sum test were used to compare continuous (age, lipoma area, and corticomedullary ratio) and ordinal (BSC and pituitary scores) data, respectively, among IR and IS horses. The test statistic of Shapiro-Wilk was used to evaluate the fit of continuous variables to a normal distribution. Correlations among continuous variables were evaluated by the method of Pearson. A mixed-model ANOVA [PROC GLIMMIX] (SAS, version 9.2, SAS Institute) was used to evaluate the association of pituitary score with total lipoma area when adjusted for age. Lipoma area was included as the dependent variable and pituitary score and age as independent variables in the model. A logistic regression procedure was used to assess the effects of insulin resistance when adjusted for age on pituitary and body condition scores. Insulin resistance was included as a class variable in the model. Body condition or pituitary scores were included as the dependent variable and insulin resistance and age as independent variables. The fit of the ANOVA models to the data was evaluated by comparing the residuals to a normal distribution. A p-value $<0.05$ was used for statistical significance in all tests.

\section{Results}

The eleven IR horses were part of an existing research herd and were assigned as IR on the basis of an SI value $<1.0 \times 10^{-4} \mathrm{~L} \cdot \mathrm{min}^{-1} \cdot \mathrm{mU}^{-1}$ (Table 1 ). History and physical examination findings for IR horses included regional adiposity, lameness, and hoof changes consistent with laminitis. Nineteen horses were deemed IS on the basis of a resting insulin $<20 \mu \mathrm{U} / \mathrm{mL}$ (Table 2). Summary data for the IR and IS horses are listed in Table 3.

In both IS and IR horses, pituitary scores were positively correlated with increasing age $(r=0.56, p=0.0013)$, but gender was not an association. When compared to IS horses $(n=19)$, IR horses $(n=11)$ had significantly higher pituitary scores $(\mathrm{p}=0.0035)$ and BCS $(\mathrm{p}=0.0001)$, even when adjusted for age. Significantly more IR horses than IS horses had lipomas $(100 \%$ vs. $58 \%$, respectively; $p=0.014)$, and IR horses had significantly higher lipoma area $(\mathrm{p}=0.0332)$. Regardless of insulin status, the most common site for lipomas was the mesentery of the small intestine.

All horses with a pituitary score $\geq 3$ were significantly more likely ( $p<0.0002)$ to have lipomas than horses with lower pituitary scores, as all horses with high pituitary scores $(\geq 3 ; 17 / 17 ; 100 \%$; average age of 16.4 years) had lipomas, whereas only 5/13 (38\%; average age 10.7 years) of horses with lower $(<3)$ pituitary scores had mesenteric lipomas. Age $(\mathrm{r}=0.51, \mathrm{p}=0.004)$ was also positively correlated with total lipoma area in both IS and IR horses. Additionally, all horses with a pituitary score $\geq 3$ had a significantly higher BCS than those with lower pituitary scores $(\mathrm{p}=0.0313)$. There was no correlation between BCS and total lipoma area or lipoma frequency.

There was no significant association between IR and adrenal corticomedullary ratio nor pituitary score and adrenal corticomedullary ratio, and no significant microscopic lesions were noted in sections of pancreas. Mild hepatocellular glycogen accumulation and/or mild lymphoplasmacytic portal hepatitis were detected in liver sections from all groups. 
Table 1. Individual data for insulin-resistant horses. ${ }^{\mathrm{a}}$

\begin{tabular}{|c|c|c|c|c|c|c|c|c|}
\hline Horse & $\begin{array}{c}\text { Age } \\
\text { (years) }\end{array}$ & Breed & Sex & $\begin{array}{l}\text { BCS } \\
(0-9)\end{array}$ & $\begin{array}{c}\mathrm{SI} \times 10^{-4} \\
\left(\mathrm{~L} \cdot \mathrm{min}^{-1} \cdot \mathrm{mU}^{-1}\right)\end{array}$ & $\begin{array}{c}\text { Pituitary Score } \\
(1-5)\end{array}$ & $\begin{array}{l}\text { Adrenal Cortex: } \\
\text { medulla }\end{array}$ & $\begin{array}{l}\text { Total Lipoma } \\
\text { area }\left(\mathrm{cm}^{2}\right)\end{array}$ \\
\hline 1 & 7 & TWH & F & 8.5 & 0.108 & 3 & 4.4 & 1.5 \\
\hline 2 & 10 & MFT & G & 8.5 & 0.949 & 3 & 3.1 & 23.0 \\
\hline 3 & 14 & Paso Fino & $\mathrm{G}$ & 9 & 0.093 & 4 & 4.8 & 0.5 \\
\hline 4 & 15 & Mixed & G & 7 & 0.758 & 3 & 3.1 & 51.0 \\
\hline 5 & 15 & $\mathrm{KSH}$ & $\mathrm{F}$ & 8.5 & 0.195 & 4 & 2.7 & 0.3 \\
\hline 6 & 15 & Mixed & G & 7 & 0.026 & 3 & 5.0 & 29.3 \\
\hline 7 & 16 & Paso Fino & $\mathrm{F}$ & 9 & 0.898 & 4 & 2.8 & 49.2 \\
\hline 8 & 17 & Mixed & $\mathrm{F}$ & 7 & 0.021 & 3 & 4.5 & 23.5 \\
\hline 9 & 17 & Morgan & G & 8.5 & 0.115 & 4 & 2.5 & 9.4 \\
\hline 10 & 17 & Paso Fino & $\mathrm{G}$ & 7.5 & 0.036 & 4 & 3.6 & 4.6 \\
\hline 11 & 22 & Mixed & $\mathrm{F}$ & 7 & 0.504 & 3 & 3.8 & 55.5 \\
\hline
\end{tabular}

${ }^{\mathrm{a}} \mathrm{KSH}=$ Kentucky Saddle Horse; MFT = Missouri Fox Trotter; TWH = Tennessee Walking Horse; G = gelding; F = female; BCS = body condition score.

Table 2. Individual data for insulin-sensitive horses. ${ }^{\text {a }}$

\begin{tabular}{|c|c|c|c|c|c|c|c|c|}
\hline Horse & $\begin{array}{c}\text { Age } \\
\text { (years) }\end{array}$ & Breed & Sex & $\begin{array}{l}\text { BCS } \\
(0-9)\end{array}$ & $\begin{array}{l}\text { Resting insulin } \\
(\mu \mathrm{U} / \mathrm{mL})\end{array}$ & $\begin{array}{c}\text { Pituitary } \\
\text { score }(1-5)\end{array}$ & $\begin{array}{l}\text { Adrenal cortex: } \\
\text { medulla }\end{array}$ & $\begin{array}{c}\text { Total lipoma } \\
\text { area }\left(\mathrm{cm}^{2}\right)\end{array}$ \\
\hline 1 & 3 & TWH & G & 4 & 2.7 & 2 & 3.0 & 0.0 \\
\hline 2 & 4 & $\mathrm{AQH}$ & $\mathrm{F}$ & 3.5 & 10.2 & 2 & 2.7 & 1.5 \\
\hline 3 & 5 & Arab & $\mathrm{F}$ & 5 & 3.6 & 1 & 4.9 & 0.0 \\
\hline 4 & 6 & Paint & G & 4.5 & 6.8 & 1 & 3.2 & 0.0 \\
\hline 5 & 7 & Paint & G & 6 & 5.1 & 2 & 2.5 & 0.0 \\
\hline 6 & 9 & $\mathrm{AQH}$ & $\mathrm{F}$ & 3 & 5.4 & 2 & 2.9 & 0.0 \\
\hline 7 & 12 & Saddlebred & G & 8 & 10.6 & 2 & 6.2 & 20.4 \\
\hline 8 & 12 & TWH & G & 2.5 & 1.6 & 2 & 4.6 & 0.0 \\
\hline 9 & 13 & Paint & $\mathrm{F}$ & 6.5 & 6.8 & 2 & 3.0 & 0.0 \\
\hline 10 & 14 & TWH & G & 5 & 16.1 & 2 & 2.4 & 0.0 \\
\hline 11 & 14 & TWH & G & 6 & 8.6 & 3 & 3.3 & 8.0 \\
\hline 12 & 15 & Appaloosa & G & 3 & 3.2 & 4 & 3.7 & 2.5 \\
\hline 13 & 15 & Mixed & G & 3 & 6.0 & 2 & 3.3 & 5.3 \\
\hline 14 & 16 & TWH & G & 3.5 & 17.4 & 4 & 1.8 & 38.8 \\
\hline 15 & 19 & TWH & G & 3 & 6.9 & 2 & 4.6 & 11.3 \\
\hline 16 & 20 & $\mathrm{AQH}$ & $\mathrm{F}$ & 4 & 2.8 & 2 & 2.7 & 7.4 \\
\hline 17 & 20 & $\mathrm{NSH}$ & $\mathrm{F}$ & 2.5 & 4.4 & 4 & 4.2 & 15.5 \\
\hline 18 & 24 & $\mathrm{AQH}$ & G & 2 & 5.6 & 3 & 4.8 & 51.5 \\
\hline 19 & 25 & $\mathrm{AQH}$ & $\mathrm{F}$ & 2.5 & 8.0 & 4 & 2.4 & 11.3 \\
\hline
\end{tabular}

${ }^{\mathrm{a}} \mathrm{AQH}=$ American Quarter Horse; NSH = National Show Horse; TWH = Tennessee Walking Horse; G = gelding; F = female; BCS = body condition score.

Table 3. Summary data for and significant differences between insulin-resistant and insulin-sensitive horses, listed as median. ${ }^{\text {a }}$

\begin{tabular}{ccccccc}
\hline Type & $\begin{array}{c}\text { Age } \\
(\text { years })\end{array}$ & $\begin{array}{c}\text { Sex } \\
\text { F:G }\end{array}$ & $\begin{array}{c}\text { BCS } \\
(\mathbf{0 - 9})\end{array}$ & $\begin{array}{c}\text { Pituitary score } \\
(\mathbf{1 - 5})\end{array}$ & $\begin{array}{c}\text { Adrenal cortex: Percent with } \\
\text { medulla }\end{array}$ & $\begin{array}{c}\text { Total lipoma } \\
\text { lipomas }\end{array}$ \\
\hline area $\left(\mathbf{c m}^{\mathbf{2}}\right)$
\end{tabular}

${ }^{\mathrm{a}} \mathrm{F}=$ female $; \mathrm{G}=$ gelding; $\mathrm{BCS}=$ body condition score $;{ }^{\mathrm{b}} \mathrm{p}=0.0001 ;{ }^{\mathrm{c}} \mathrm{p}=0.0035 ;{ }^{\mathrm{d}} \mathrm{p}=0.014 ;{ }^{\mathrm{e}} \mathrm{p}=0.0332$. 


\section{Discussion}

Insulin resistance was associated with a higher BCS and higher pituitary score in the horses examined in the current study. Additionally, a higher frequency of mesenteric lipomas and a greater lipoma area were identified in IR horses. Similarly, horses with a pituitary score $\geq 3$ (diffuse pars intermedia hyperplasia) also had a higher frequency of mesenteric lipomas. An association between increasing pituitary scores and age was also identified.

Obesity is associated with increased oxidative stress in humans [19], and increased concentrations of the acute phase protein SAA have been associated with both obesity and IR in horses [20]. Acute phase proteins are increased as part of the response to inflammatory stimuli, and therefore, obesity may also result in low-grade inflammation and oxidative stress. Oxidative stress could then lead to degeneration of dopaminergic neurons and loss of inhibition at the level of the pituitary pars intermedia [21]. Loss of dopaminergic inhibition permits hyperplasia and dysregulation of the pars intermedia [22] [23]. Obese horses might therefore be predisposed to developing PPID. Alternatively, metabolic alterations associated with pituitary disease could result in obesity. Further studies are required to clarify the relationship between pituitary lesions and obesity.

In the current study, IR was associated with higher BCS and higher pituitary scores, independent of age. Insulin resistance has been attributed to the effects of obesity-associated oxidative stress, inflammation, and increased production of pro-inflammatory cytokines on insulin sensitivity [19] [24]. Furthermore, higher insulin concentrations have been identified in horses with clinical PPID4 and those with pituitary adenomas [13]. Horses with PPID often also have increased plasma $\alpha$-MSH levels, which have also been correlated with an increased BCS [14]. Unfortunately, since previous research has shown that histologic lesions in the pars intermedia do not always correlate with clinical signs [25], and since horses in the current study did not undergo diagnostic testing for PPID, the health implications of concurrent IR and pituitary lesions require further study. The results of this study, do, however, confirm previous reports that increasing pituitary scores are correlated with increasing age [18] [20].

In this study, IR horses were significantly more likely to have mesenteric lipomas and had significantly greater lipoma areas than did IS horses. Similarly, horses with a pituitary score $\geq 3$ (diffuse pars intermedia hyperplasia) were significantly more likely to have mesenteric lipomas than horses with pituitary scores $<3$. However, since IR was also associated with higher pituitary scores, it was difficult to determine which was responsible for the increase in lipoma area.

The current study fails to identify any relationships between BCS and lipoma frequency or area. This contradicts the previously reported association between mesenteric lipomas and obesity [3]. Our findings suggest that IR horses and those with higher pituitary scores, regardless of BCS, may be more likely to have lipomas, and therefore may be more likely to develop lipoma-associated colic.

Although adrenal cortical hyperplasia is commonly associated with proliferative pituitary lesions in other species, it is uncommon in horses [10] [17]. Likewise, there was no association between pituitary score and adrenal corticomedullary ratio in the current study. Microscopic evaluation of sections of liver and pancreas from horses in all groups revealed only mild changes, which were considered normal background lesions. Alterations in glucose metabolism were not associated with microscopic lesions in the pancreas. Beta cell density and distribution were not assessed in this study.

\section{Conclusion}

An association between IR and increasing pituitary score is detected in this study, indicating that both conditions can occur concurrently. In addition, both horses with IR and those with high pituitary scores have a higher frequency of mesenteric lipomas, and these factors may increase the likelihood of lipoma-associated colic in affected horses.

\section{Acknowledgements}

The authors thank Misty Bailey for technical editing of the manuscript.

\section{References}

[1] Kahn, C.R. (1978) Insulin Resistance, Insulin Insensitivity, and Insulin Unresponsiveness: A Necessary Distinction. Metabolism, 27, 1893-1902. http://dx.doi.org/10.1016/S0026-0495(78)80007-9 
[2] Bergman, R.N., Phillips, L.S. and Cobelli, C. (1981) Physiologic Evaluation of Factors Controlling Glucose Tolerance in Man: Measurement of Insulin Sensitivity and Beta-Cell Glucose Sensitivity from the Response to Intravenous Glucose. The Journal of Clinical Investigation, 68, 1456-1467. http://dx.doi.org/10.1172/JCI110398

[3] Boston, R.C., Stefanovski, D., Moate, P.J., Sumner, A.E., Watanabe, R.M. and Bergman, R.N. (2003) MINMOD Millennium: A Computer Program to Calculate Glucose Effectiveness and Insulin Sensitivity from the Frequently Sampled Intravenous Glucose Tolerance Test. Diabetes Technology \& Therapeutics, 5, 1003-1015. http://dx.doi.org/10.1089/152091503322641060

[4] Treiber, K.H., Kronfeld, D.S. and Geor, R.J. (2006) Insulin Resistance in Equids: Possible Role in Laminitis. Journal of Nutrition, 136, S2094-S2098.

[5] Firshman, A.M. and Valberg, S.J. (2007) Factors Affecting Clinical Assessment of Insulin Sensitivity in Horses. Equine Veterinary Journal, 39, 567-575. http://dx.doi.org/10.2746/042516407X238512

[6] Hoffman, R.M., Boston, R.C., Stefanovski, D., Kronfeld, D.S. and Harris, P.A. (2003) Obesity and Diet Affect Glucose Dynamics and Insulin Sensitivity in Thoroughbred Geldings. Journal of Animal Science, 81, 2333-2342.

[7] Edwards, G.B. and Proudman, C.J. (1994) An Analysis of 75 Cases of Intestinal Obstruction Caused by Pedunculated Lipomas. Equine Veterinary Journal, 26, 18-21. http://dx.doi.org/10.1111/j.2042-3306.1994.tb04324.x

[8] Brown, C.C., Baker, D.C. and Barker, I.K. (2007) Alimentary System. In: Maxie, M.G., Ed., Jubb, Kennedy and Palmer's Pathology of Domestic Animals, 5th Edition, Vol. 2, Saunders Elsevier, Edinburgh, 1-296.

[9] Vincent, H.K., Innes, K.E. and Vincent, K.R. (2007) Oxidative Stress and Potential Interventions to Reduce Oxidative Stress in Overweight and Obesity. Diabetes, Obesity \& Metabolism, 9, 813-839. http://dx.doi.org/10.1111/j.1463-1326.2007.00692.x

[10] Suagee, J.K., Corl, B.A., Crisman, M.V., Pleasant, R.S., Thatcher, C.D. and Geor, R.J. (2013) Relationships between Body Condition Score and Plasma Inflammatory Cytokines, Insulin, and Lipids in a Mixed Population of Light-Breed Horses. Journal of Veterinary Internal Medicine, 27, 157-163. http://dx.doi.org/10.1111/jvim.12021

[11] Klinkhamer, K., Menheere, P.P.C.A. and van der Kolk, J.H. (2011) Basal Glucose Metabolism and Peripheral Insulin Sensitivity in Equine Pituitary Pars Intermedia Dysfunction. The Veterinary Quarterly, 31, 19-28. http://dx.doi.org/10.1080/01652176.2011.570127

[12] McGowan, C.M., Frost, R., Pfeiffer, D.U. and Neiger, R. (2004) Serum Insulin Concentrations in Horses with Equine Cushing's Syndrome: Response to a Cortisol Inhibitor and Prognostic Value. Equine Veterinary Journal, 36, $295-298$. http://dx.doi.org/10.2746/0425164044877288

[13] van der Kolk, J.H., Wensing, T., Kalsbeek, H.C. and Breukink, H.J. (1995) Laboratory Diagnosis of Equine Pituitary Pars Intermedia Adenoma. Domestic Animal Endocrinology, 12, 35-39. http://dx.doi.org/10.1016/0739-7240(94)00006-M

[14] Donaldson, M.T., McFarlane, D., Jorgensen, A.J.R. and Beech, J. (2004) Correlation between Plasma $\alpha$-MelanocyteStimulating Hormone Concentration and Body Mass Index in Healthy Horses. American Journal of Veterinary Research, 65, 1469-1473. http://dx.doi.org/10.2460/ajvr.2004.65.1469

[15] Toth, F., Frank, N., Elliott, S.B., Perdue, K., Geor, R.J. and Boston, R.C. (2009) Optimisation of the Frequently Sampled Intravenous Glucose Tolerance Test to Reduce Urinary Glucose Spilling in Horses. Equine Veterinary Journal, 41, 844-851. http://dx.doi.org/10.2746/042516409X439661

[16] Freestone, J.F., Wolfsheimer, K.J., Kamerling, S.G., Church, G., Hamra, J. and Bagwell, C. (1991) Exercise Induced Hormonal and Metabolic Changes in Thoroughbred Horses: Effects of Conditioning and Acepromazine. Equine Veterinary Journal, 23, 219-223. http://dx.doi.org/10.1111/j.2042-3306.1991.tb02760.x

[17] Heinrichs, M., Baumgartner, W. and Capen, C.C. (1990) Immunocytochemical Demonstration of ProopiomelanocortinDerived Peptides in Pituitary Adenomas of the Pars Intermedia in Horses. Veterinary Pathology, 27, 419-425. http://dx.doi.org/10.1177/030098589902700606

[18] Miller, M.A., Pardo, I.D., Jackson, L.P., Moore, G.E. and Sojka, J.E. (2008) Correlation of Pituitary Histomorphometry with Adrenocorticotropic Hormone Response to Domperidone Administration in the Diagnosis of Equine Pituitary Pars Intermedia Dysfunction. Veterinary Pathology, 45, 26-38. http://dx.doi.org/10.1354/vp.45-1-26

[19] Hardy, O.T., Czech, M.P. and Corvera, S. (2012) What Causes the Insulin Resistance Underlying Obesity? Current Opinions in Endocrinology, Diabetes, and Obesity, 19, 81-87. http://dx.doi.org/10.1097/MED.0b013e3283514e13

[20] Tadros, E.M. and Frank, N. (2011) Endocrine Disorders and Laminitis. Equine Veterinary Education, 25, 152-162. http://dx.doi.org/10.1111/j.2042-3292.2011.00327.x

[21] Frank, N., Geor, R.J., Bailey, S.R., Durham, A.E. and Johnson, P.J. (2010) Equine Metabolic Syndrome. Journal of Veterinary Internal Medicine, 24, 467-475. http://dx.doi.org/10.1111/j.1939-1676.2010.0503.x

[22] McFarlane, D. (2011) Equine Pituitary Pars Intermedia Dysfunction. Veterinary Clinics of North America: Equine 
Practice, 27, 93-113. http://dx.doi.org/10.1016/j.cveq.2010.12.007

[23] McFarlane, D., Dybdal, N., Donaldson, M.T., Miller, L. and Cribb, A.E. (2005) Nitration and Increased $\alpha$-Synuclein Expression Associated with Dopaminergic Neurodegeneration in Equine Pituitary Pars Intermedia Dysfunction. Journal of Neuroendocrinology, 17, 73-80. http://dx.doi.org/10.1111/j.1365-2826.2005.01277.x

[24] Carter, R.A., McCutcheon, L.J., George, L.A., Smith, T.L., Frank, N. and Geor, R.J. (2009) Effects of Diet-Induced Weight Gain on Insulin Sensitivity and Plasma Hormone and Lipid Concentrations in Horses. American Journal of Veterinary Research, 70, 1250-1258. http://dx.doi.org/10.2460/ajvr.70.10.1250

[25] van der Kolk, J.H., Heinrichs, M., van Amerongen, J.D., Stooker, R.C.J., Jansen in de Wal, L. and van den Ingh, T.S.G.A.M. (2004) Evaluation of Pituitary Gland Anatomy and Histopathologic Findings in Clinically Normal Horses and Horses and Ponies with Pituitary Pars Intermedia Adenoma. American Journal of Veterinary Research, 65, 17011707. http://dx.doi.org/10.2460/ajvr.2004.65.1701 
Scientific Research Publishing (SCIRP) is one of the largest Open Access journal publishers. It is currently publishing more than 200 open access, online, peer-reviewed journals covering a wide range of academic disciplines. SCIRP serves the worldwide academic communities and contributes to the progress and application of science with its publication.

Other selected journals from SCIRP are listed as below. Submit your manuscript to us via either submit@scirp.org or Online Submission Portal.
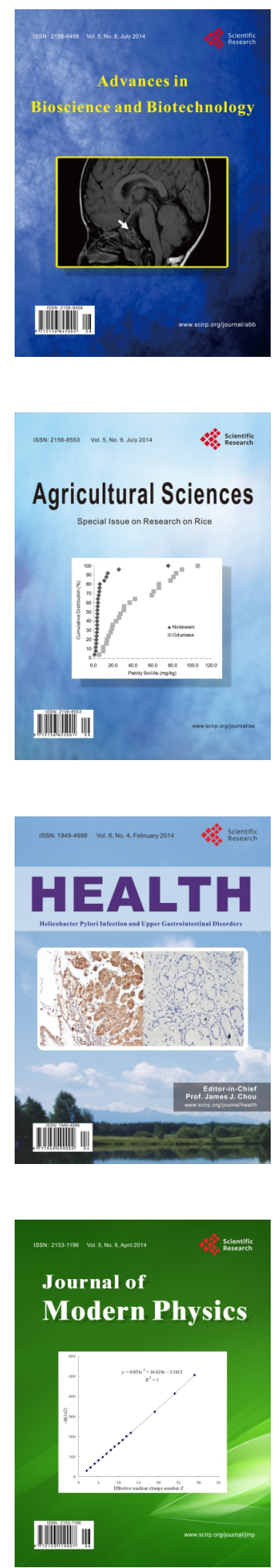
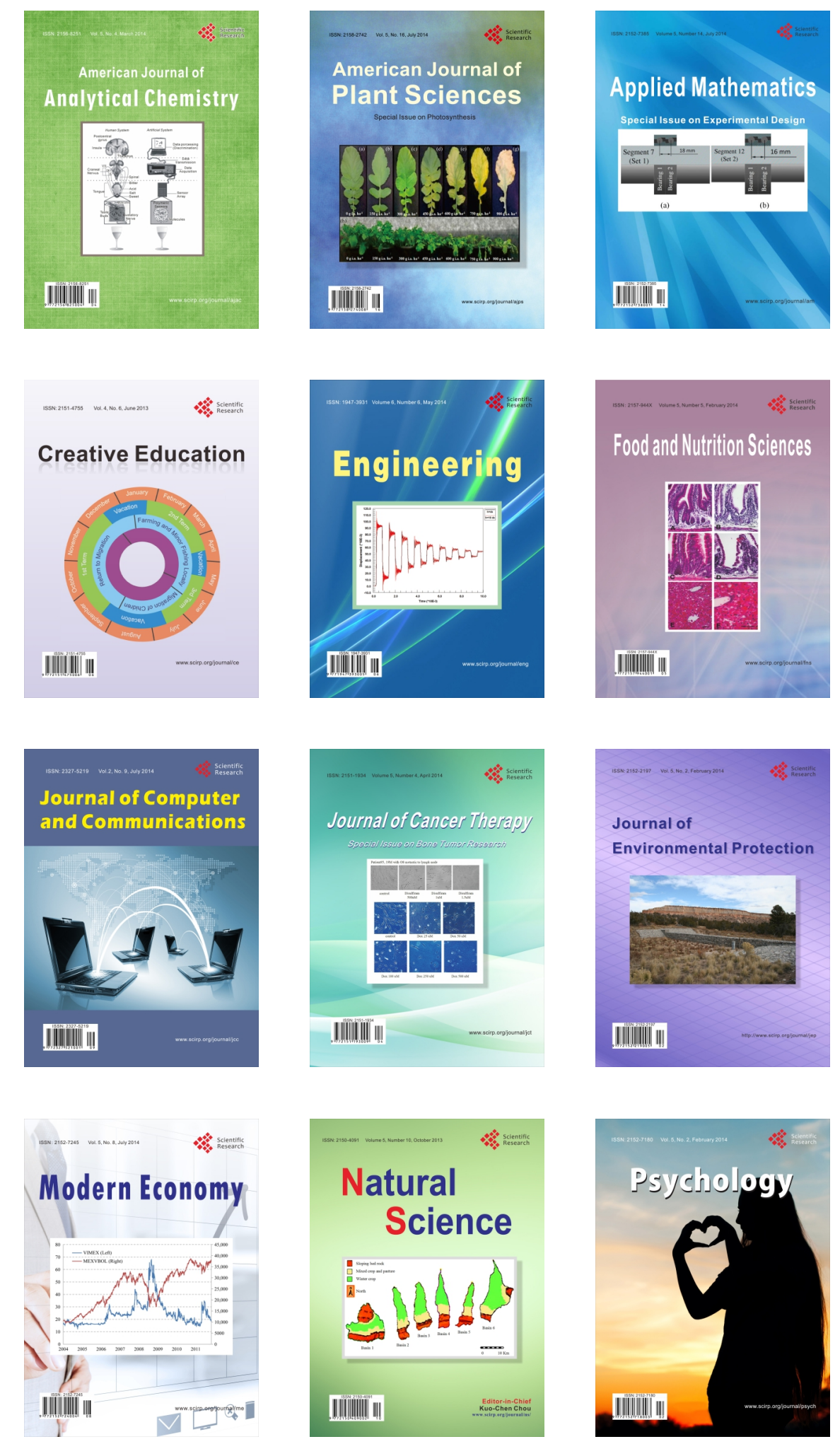